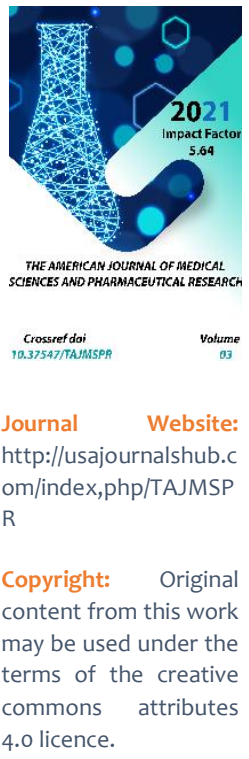

\title{
Features Of The Pathogenesis And Correction Of Anemia Induced By Antiviral Therapy For Hepatitis C
}

\author{
Ismatova Mekhriniso Nasritdinovna \\ Bukhara State Medical Institute, Uzbekistan \\ Nurullaeva Dilnoza Fatullevna \\ Bukhara State Medical Institute, Uzbekistan
}

\section{ABSTRACT}

$\mathrm{HCV}$ infection remains one of the leading problems in the diagnosis and treatment of chronic liver disease, given the scale of hepatitis $C$ virus infection worldwide, the significant number of unexamined but at-risk patients, and the incidence of cirrhosis and liver cancer. Anemia is the most common hematological adverse event, which in turn significantly reduces the quality of life of patients during antiviral therapy, their adherence to treatment, and increases the risk of developing cardiovascular, renal and cerebral disorders.

\section{KEYWORDS}

Anemia, hepatitis C, antiviral therapy

\section{INTRODUCTION}

$\mathrm{HCV}$ infection remains one of the leading problems in the diagnosis and treatment of chronic liver disease, given the scale of hepatitis $C$ virus infection worldwide, the 
significant number of unexamined but at-risk patients, and the incidence of cirrhosis and liver cancer. Today, all stages of diagnosis of chronic HCV infection are available in Ukraine, including the possibility of non-invasive determination of the stage of fibrosis. The approved world standards of antiviral therapy, the availability of the necessary drugs on the pharmaceutical market of our country and more than 10 years of experience in their use allow us to provide medical care to this category of patients at the modern level. However, there are a number of problems that the doctor and the patient face during the course of antiviral therapy. Solving these problems becomes a priority in the tactics of patient management and requires a qualified individual approach in each clinical situation. One of these intractable problems is the correction of adverse events of antiviral therapy (AVT). Almost all patients receiving treatment with peginterferon and ribavirin develop one or more adverse events during therapy, which can worsen not only the patient's well-being and condition, but are also the main reason for modifying drug doses or completely discontinuing therapy. Effective control of unwanted effects makes it possible to complete a full course of antiviral therapy; therefore, it is considered one of the promising approaches to improving the results of HCV infection treatment $(1,3)$. The results of numerous controlled studies, including the IDEAL study (2), as well as more than 10 years of experience in the use of combined antiviral therapy in clinical practice, make it possible to determine the incidence of severe side effects in $9-12 \%$ of patients, discontinuation of treatment due to the development of side effects. actions in $10-13 \%$ of cases. Of the most frequently occurring undesirable effects, flulike syndrome, irritation at the injection site, alopecia, irritability, depression, insomnia, hematological adverse events (anemia, neutropenia, thrombocytopenia) should be noted. The problem of correcting adverse events becomes even more urgent with the beginning of the era of triple therapy for chronic hepatitis $C$, since the incidence of some of them increases dramatically when standard therapy is used in combination with NS-3 protease inhibitors. Side effects from triple therapy include the usual side effects seen with IFN / RBV combination therapy, as well as an increased incidence of anemia $(3,4)$. On average, the decrease in hemoglobin levels during triple therapy was approximately $1 \mathrm{~g} /$ $\mathrm{dL}$, which was higher than the values observed with PEGIFN / RBV; in about half of the patients, the hemoglobin level decreased by more than $10 \mathrm{~g} / \mathrm{dL}(6,7)$.

\section{MATERIAL AND METHODS}

Anemia is the most common hematological adverse event, which in turn significantly reduces the quality of life of patients during antiviral therapy, their adherence to treatment, and increases the risk of developing cardiovascular, renal and cerebral disorders (3).

WHO defines the criteria for anemia for men as a decrease in hemoglobin level less than $130 \mathrm{~g} /$ I and hematocrit less than 39\%; for women - a decrease in the level of hemoglobin less than $120 \mathrm{~g} / \mathrm{I}$ and a hematocrit of less than $36 \%$. Depending on the severity of the decrease in the level of hemoglobin, three degrees of severity of anemia are distinguished: mild - the level of hemoglobin is above $90 \mathrm{~g} / \mathrm{l}$; average hemoglobin in the range of 90-70 $\mathrm{g} / \mathrm{l}$; severe the hemoglobin level is less than $70 \mathrm{~g} / \mathrm{I}(8)$.

\section{RESULTS AND DISCUSSION}

The incidence of anemia in patients receiving combination antiviral therapy has been evaluated in clinical trials. In the previously mentioned IDEAL study, in $28 \%$ of cases, the identified anemia required a change in the dose of ribavirin and / or the appointment of 
erythropoietin with a decrease in hemoglobin level less than $10 \mathrm{~g} / \mathrm{dl}$, more pronounced anemia (a decrease in hemoglobin less than 8.5 $\mathrm{g} / \mathrm{dl}$ ) was observed in $2.1-3.8 \%$ of patients (9). Other studies $(10,11,12,13)$ have shown that anemia develops in $10-30 \%$ of cases against the background of antiviral therapy. A decrease in the concentration of hemoglobin by more than $25 \%$ from the initial and an increase in the level of indirect bilirubin in the blood serum, requiring an individual selection of the dose of the drug or discontinuation of ribavirin, are noted in $20 \%$ of patients during the first $2-4$ weeks of treatment with ribavirin. A decrease in hemoglobin to a level of less than $120 \mathrm{~g} / \mathrm{L}$ during the combined AVT period is detected in $52 \%$ of patients (14).

Risk factors for the development of anemia were determined by the female sex, the initial hemoglobin concentration is less than $140 \mathrm{~g} / \mathrm{L}$, the age is over 60 years, the ribavirin dose is $\geq$ $12 \mathrm{mg} / \mathrm{kg}$, the degree of hemoglobin level decrease after 2 weeks, the decrease in creatinine clearance, the Mongoloid race (1, 15).

The leading pathogenetic aspects of anemia formation against the background of combined antiviral therapy in patients with hepatitis $C$ are the myelosuppressive effect of interferon- $\alpha$, impaired renal erythropoietin production, immune hemolysis, and activation of erythroid stem cell apoptosis. Before starting treatment, it is also necessary to exclude iron deficiency, which may contribute to the pathogenesis of anemia in patients with liver disease, especially in women of reproductive age.

The dominant factor in the development of anemia in the presence of AVT is the use of ribavirin at a dose of $\geq 800 \mathrm{mg} /$ day. The mechanisms of development of ribavirininduced anemia are shown in Fig. 1 $(6,7)$.
Ribavirin accumulates in erythrocytes, where it undergoes phosphorylation to pharmacologically active forms - mono-, di-, and ribavirin triphosphates, which are very slowly excreted from the erythrocyte (half-life up to 40 days). While these metabolites are excreted from plasma much faster (half-life up to 24 hours). By 2-4 weeks of AVT, the concentration of ribavirin in the body reaches stable levels, and by this time its concentration in erythrocytes is 60 times higher than in plasma (3). Ribavirin metabolites cause inhibition of intracellular energy metabolism and oxidative damage to the erythrocyte membrane, which leads to increased intravascular hemolysis under the action of the reticuloendothelial system (1). Thus, it is the accumulation of ribavirin metabolites in erythrocytes that leads to the development of hemolysis.

One of the new widely discussed mechanisms for the development of ribavirin-induced anemia is the polymorphism of a single nucleotide rs6051702, located on chromosome 20 in the region of the gene encoding the synthesis of the enzyme inosine triphosphatase (ITPase), which causes the accumulation of inosine triphosphatase (ITP) (3). Two functional variants of the ITPase gene have been identified, which are closely associated with the risk of developing ribavirininduced anemia. It was found that the single nucleotide polymorphism rs6051702 correlates with a decrease in hemoglobin level $>3.0 \mathrm{~g} / \mathrm{dL}$ from baseline or total level <10.0 g/ dL by 4 weeks of AVT. It is possible that the prospects for genotyping the polymorphism of a single nucleotide of the ITPase in everyday practice will solve the problem of predicting and preventing the development of anemia in the presence of $\operatorname{AVT}(3,4)$.

The clinical significance of the development of anemia is twofold. On the one hand, with the development of anemia, weakness, fatigue, 
shortness of breath increase, which significantly worsens the tolerance of therapy and in some cases requires modification (up to complete cancellation) of the dose of ribavirin. On the other hand, according to the IDEAL study (9), a higher rate of achieving a sustained virological response was observed in patients with anemia compared with patients in whom the hemoglobin level did not significantly decrease during treatment $(48.8 \%$ and $36.7 \%$, respectively, $\mathrm{p}<0.001)$.

According to the EASL-2011 recommendations for the management of patients with chronic hepatitis $C$, if the hemoglobin level decreases $<10 \mathrm{~g} / \mathrm{dL}$ when prescribing standard therapy with pegylated interferon and ribavirin, the dose of ribavirin should be adjusted downward by $200 \mathrm{mg}$ at a time. If the hemoglobin level falls below $8.5 \mathrm{~g} / \mathrm{dL}$, ribavirin should be discontinued. Growth factors can be used as an alternative to maintain treatment with high doses of pegylated interferon and / or ribavirin $(10,11,12)$.

The use of growth factor (preparations of recombinant erythropoietin), although it improves the well-being of patients and reduces the need to reduce the dose of ribavirin, according to different authors (15) did not increase the frequency of a persistent virological response. However, in contrast to these results, there is now evidence that the use of adjuvant therapy with erythropoietin preparations significantly affects the outcome of antiviral therapy. Such data were obtained in the study by K. Falasca et al. with the participation of 42 patients with chronic hepatitis $C$ who, against the background of standard AVT, showed a decrease in hemoglobin level by at least $2.5 \mathrm{~g} / \mathrm{dL}$, were randomized into two representative groups. The first group $(n=22)$ received epoetin- $\beta$ 30,000 units subcutaneously once a week. For patients in the second group $(n=20)$, the dose of ribavirin was reduced to $600 \mathrm{mg} /$ day. The frequency of achieving a persistent virological response in the first group (82\%) was significantly higher than in the second (45\%), p $=0.003$ (10). The same study design was applied in a larger analysis by Bertino $\mathrm{G}$. et al. (11) involving 134 patients. The authors have shown that the use of the stimulant erythropoietin was associated with a significant increase in the frequency of persistent virological response to $59.7 \%$ versus $34.4 \%$ in the group of patients who received a reduced dose of ribavirin to correct anemia. In addition, the target hemoglobin level was 13.8 \pm 1.2 in the study group and $11.5 \pm 0.8 \mathrm{~g} / \mathrm{dL}$ in the control group.

However, not everything is so unambiguous in deciding on concomitant therapy with growth factors, as well as the decision to change the course dose of ribavirin. One analysis has shown that the use of hematologic growth factors nearly doubles the cost of treating chronic hepatitis C (14). Although the use of erythropoietin and darbepoetin is generally safe, it can lead to serious adverse events, including cardiovascular and thromboembolic events, true erythrocyte aplasia, the progression of certain cancers, and death (15).

\section{CONCLUSION}

Thus, the management of patients with chronic hepatitis C, the appointment and correction of side effects of antiviral therapy today requires a doctor to know not only the characteristics of the course of chronic HCV infection, but also the ability to choose the correct treatment tactics, knowledge in related fields of medicine, timely monitoring, and adequate correction. adverse events taking into account the pharmacoeconomic aspects of standard and concomitant therapy. And if in the past we determined the "host" and "virus" factors that can determine the likelihood of achieving a persistent virological response, today we can add to them the "doctor" factor, which 
determines his professionalism, including on which the final result of treatment may depend.

\section{REFERENCES}

1. Moiseev S.V., Abdurakhmanov D.T. How to improve the results of standard antiviral therapy in patients with chronic hepatitis C: the role of hematopoietic growth factors. Clinical Pharmacology and Therapy, 2011, 20 (2), P.2 [in russian]

2. Sulkowski $M$ et al. EASL 2008. Abstract 991, Oral Presentation. [in russian]

3. Bakulin I.G., Sandler Yu.G., Sharabanov A.S. Hematological adverse events during antiviral therapy in patients with chronic hepatitis C. Hepatological Forum, 2011, 4, C.2 [in russian]

4. Kwo PY, Lawitz EJ, McCone J, et al. SEfficacy of boceprevir, an NS3 protease inhibitor, in combination with peginterferon alfa-2b and ribavirin in treatment-naive patients with genotype 1 hepatitis $C$ infection (SPRINT-1): an openlabel, randomised, multicentre phase 2 trial. Lancet 2010; 376: 705-16.

5. Berman K, Kwo PY. Boceprevir, an NS3 protease inhibitor of HCV. Clin Liver Dis 2009; 13: 429-39.

6. Poordad F, McCone J Jr, Bacon BR, et al. Boceprevir for untreated chronic HCV genotype 1 infection. N Engl J Med 2011; 364: 1195-206.

7. Jacobson IM, McHutchison JG, Dusheiko G, et al. Telaprevir for previ- ously untreated chronic hepatitis $C$ virus infection. $N$ Engl J Med 2011; 364: 2405-16.

8. www.anemia.ru

9. Sulkowski M.S., Shiffman M.L., Afdhal N.H. et al. Hepatitis $C$ virus treatment-related anemia is associated with higher sustained virologic response rate. Gastroenterology, 2010,139, 1602-16011

10. McHutchinson J., Lawitz E., Shiffman M.L. et al. Peginterferon alfa-2b or alfa-2a with ribavirin for treatment of hepatitis $\mathrm{C}$ infection. N. Engl. J. Med., 2009, 361, 580593.

11. Sakamoto N., Tanaka Y. et al. ITPA gene variant protects against anemia induced by pegylated interferon- $\alpha$ and ribavirin therapy for Japanese pa- tients with chronic hepatitis C. Hepatology Research, 2010, 40, 1063-1071/

12. Hitomi Y., Cirulli E.T., Fellay J. et al. Inosine tripfosphate protects against ribavirininduced ATP loss by restoring adenylosuccinate synthase function. Gastroenterology, 2011, 140, 1314-1321.

13. Bennett $C L$, Silver $S M$, Djulbegovic $B$, Samaras AT, Blau CA, Gleason KJ, et al. Venous thromboembolism and mortality associated with recombinant erythropoietin and darbepoetin administration for the treatment of cancerasso- ciated anemia. Jama 2008, 299, 914924.

14. Falaska K., Ucciferi C., Mancino P. et al. Use of epoetin beta during combination therapy of infection with hepatitis $C$ virus with ribavirin improves a sustained viral response. J. Med. Virol., 2010, 82(1), 49-56.

15. Bertino G., Ardiri A., Boemi P., et al. Epoetin alpha improves the response to antiviral treatment in HCV-related chronic hepatitis. Eur.J. Clin. Pharmacol., 2010, 66 (10), 10551063. 